\title{
Health and Safety Statistics
}

\section{Annual Report for Great Britain}

\section{$2014 / 15$}




\section{III health}

1.2 million people who worked during the last year were suffering from an illness they believed was caused or made worse by their work, of which $\mathbf{0 . 5}$ million were new conditions that started during the year.

A further $\mathbf{0 . 8}$ million former workers (who last worked over 12 months ago) were suffering from an illness which was caused or made worse by their past work.

2,538 people died from mesothelioma in 2013 and thousands more from other work-related cancers and diseases such as COPD.

\section{Injuries}

142 workers were killed at work, a rate of $\mathbf{0 . 4 6}$ fatalities per 100,000 workers.

$\mathbf{7 6 , 0 0 0}$ other injuries to employees were reported under RIDDOR, a rate of 293 per 100,000 employees.

611,000 injuries occurred at work according to the Labour Force Survey, of which 152,000 led to over-7-days absence, with rates of $\mathbf{2 , 0 3 0}$ and $\mathbf{5 0 0}$ per $\mathbf{1 0 0 , 0 0 0}$ workers respectively.

\section{Workplace risks}

'Dealing with difficult customers, patients, pupils etc.' and 'lifting or moving people or heavy loads' were the two most common selfreported risk factors in the workplace, in a 2014 survey of workplaces.

\section{Working days lost}

27.3 million days were lost due to work-related ill health or injury (15 days per case).

23.3 million days were lost due to work-related ill health and 4.1 million due to workplace injury.

\section{Economic costs to Britain}

Injuries and new cases of ill health resulting largely from current working conditions cost society an estimated $£ 14.3$ billion in 2013/14 (based on 2013 prices).

\section{Enforcement}

586 cases were prosecuted by HSE in England and Wales.

70 cases were prosecuted by Local authorities in England and Wales. 72 cases were prosecuted by the Procurator Fiscal in Scotland. 12,430 enforcement notices were issued by all enforcing authorities. 


\section{Fatal diseases}

- Around 13,000 deaths each year from work-related lung disease and cancer are estimated to be attributed to past exposure, primarily to chemicals and dust at work.

- This figure includes diseases for which it is possible either to count individual deaths directly, or where there is sufficient data to produce statistical estimates.

- Most of these diseases take many years to develop and so deaths occurring now are largely a result of past workplace conditions.

Most of these deaths were work-related cancers or Chronic Obstructive Pulmonary Disease (COPD).

- Current estimates (based on 2005 data) suggest there are at least 8,000 work-related cancer deaths each year in Great Britain.

More than half of these cancer deaths were caused by past exposures to asbestos (either mesothelioma or asbestos-related lung cancer).

The next four biggest categories of work-related cancer were lung cancer due to silica, diesel engine exhaust and mineral oils, and breast cancer due to shift work. *

\section{Estimated current annual deaths due to work-related diseases} (with causal agents in brackets)

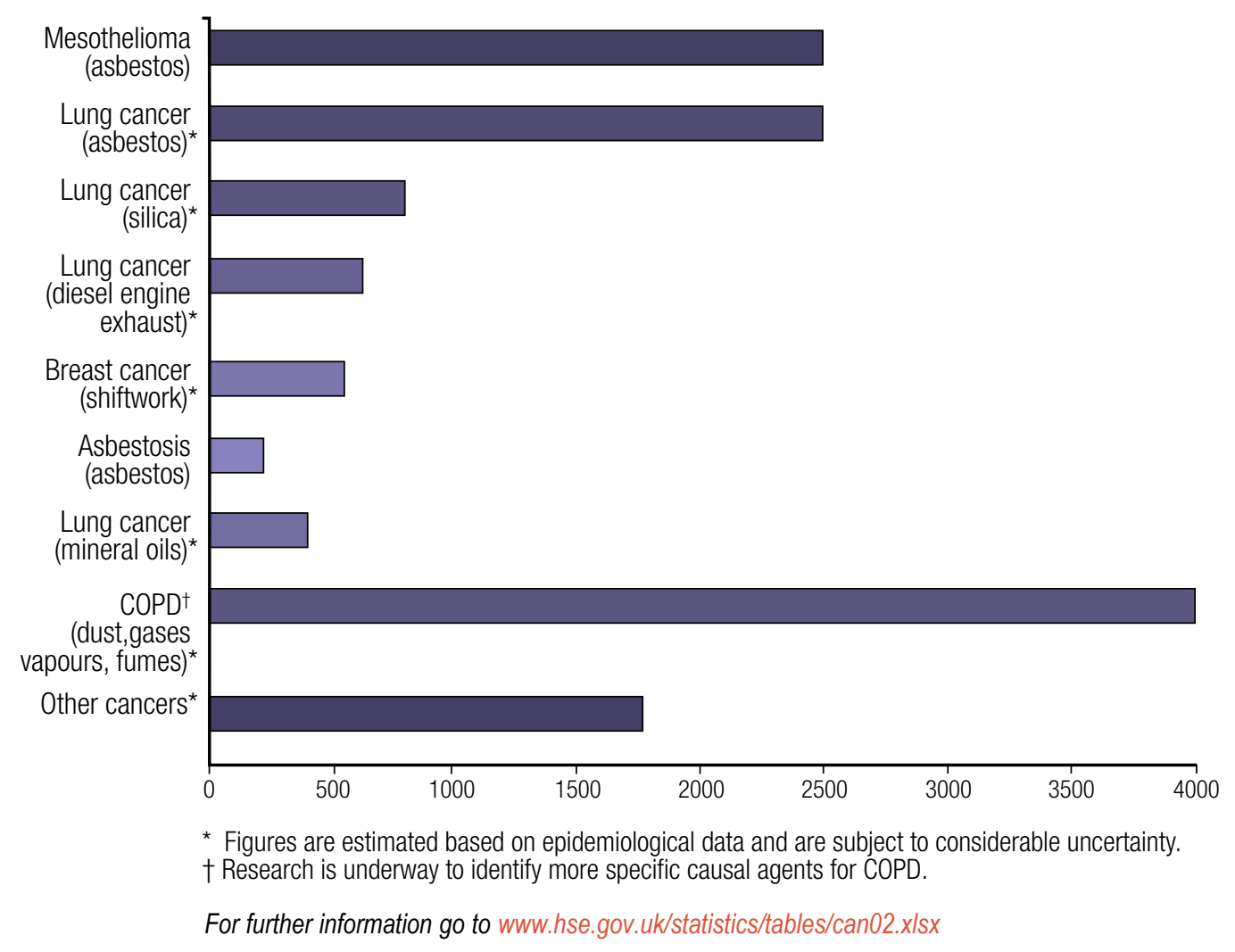

* Work-related cancer estimates are for known carcinogens (including silica, diesel engine exhaust, and mineral oils), and probable carcinogens (such as shift work) which have not yet been confirmed. 


\section{Fatal diseases (continued)}

In 2013 there were 2,538 deaths due to mesothelioma (a cancer of the lung lining) caused by past exposure to asbestos.

- The latest projections suggest there will be around 2,500 deaths per year for the rest of this current decade before annual numbers begin to decline.

- There were 2,215 new cases of mesothelioma assessed for Industrial Injuries Disablement Benefit (IIDB) in 2014 compared with 2,145 in 2013.

- Since the late 1990s, annual IIDB cases have tended to increase more rapidly than annual deaths, reflecting efforts to increase the proportion who claim over this period.

- The annual number of lung cancer deaths caused by asbestos is likely to be similar to the number of mesotheliomas.

- In 2013 there were 217 deaths where asbestosis was recorded as the underlying cause.

- There were 170 other pneumoconiosis deaths, mostly due to coal dust with a smaller number due to silica.

\section{Mesothelioma in Great Britain: annual actual and predicted deaths, and IIDB cases}

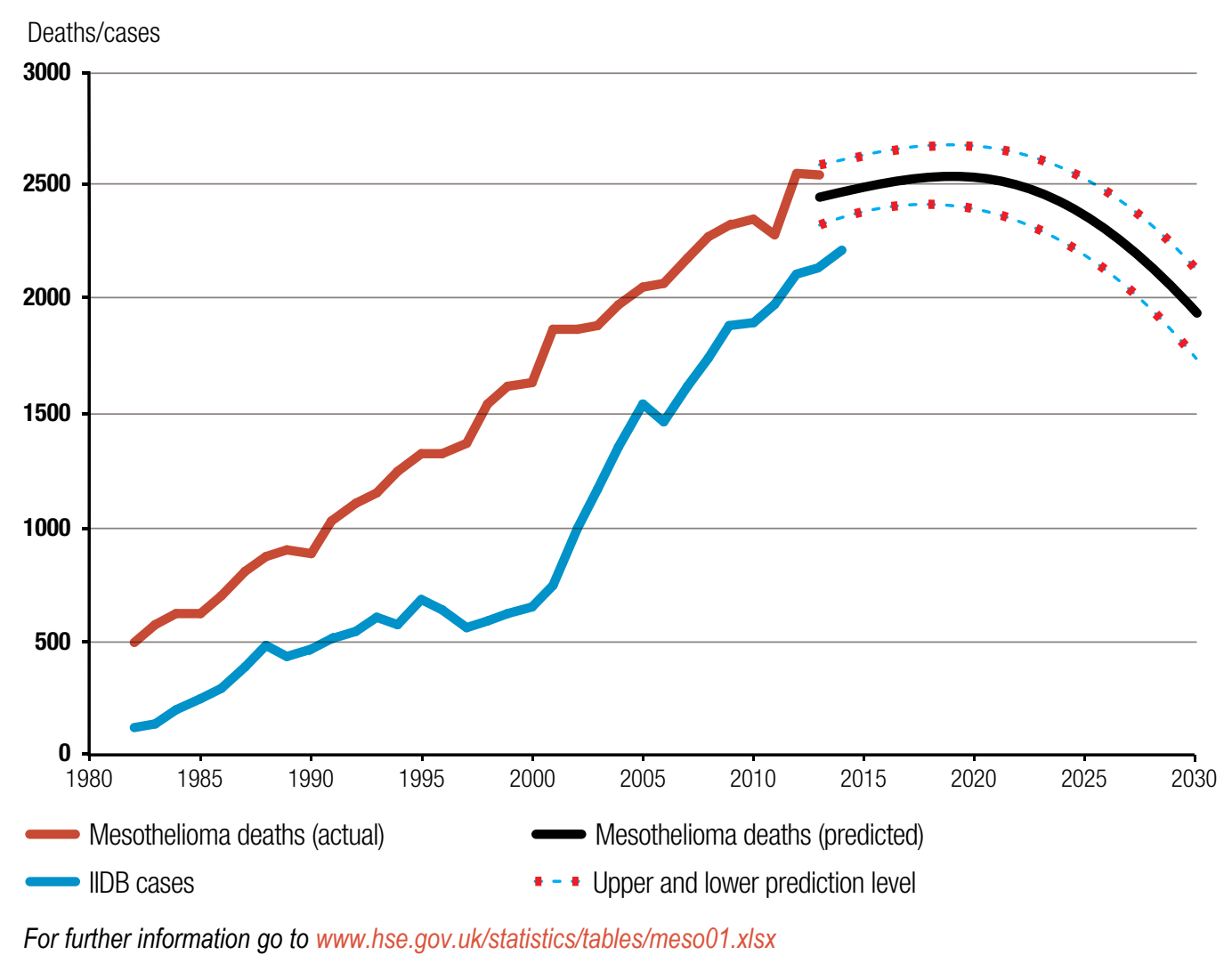




\section{Self-reported illness}

- In 2014/15 an estimated 2.0 million people were suffering from an illness (long standing as well as new cases) they believed was caused or made worse by their current or past work.

- 1.2 million worked in the last 12 months, and a further 0.8 million were former workers.

- 0.5 million were new cases amongst those working in the last 12 months.

- Around 80 per cent of new work-related conditions were either musculoskeletal disorders or stress, depression or anxiety.

\section{Change indicator for rates \\ of total ill health cases*}

\begin{tabular}{l} 
Since 2013/14 \\
\hline Since 2009/10 \\
\hline Since 2004/05 \\
\hline
\end{tabular}

${ }^{*}$ For people working in the last 12 months

\section{Self-reported illness caused or made worse by work, 2014/15}

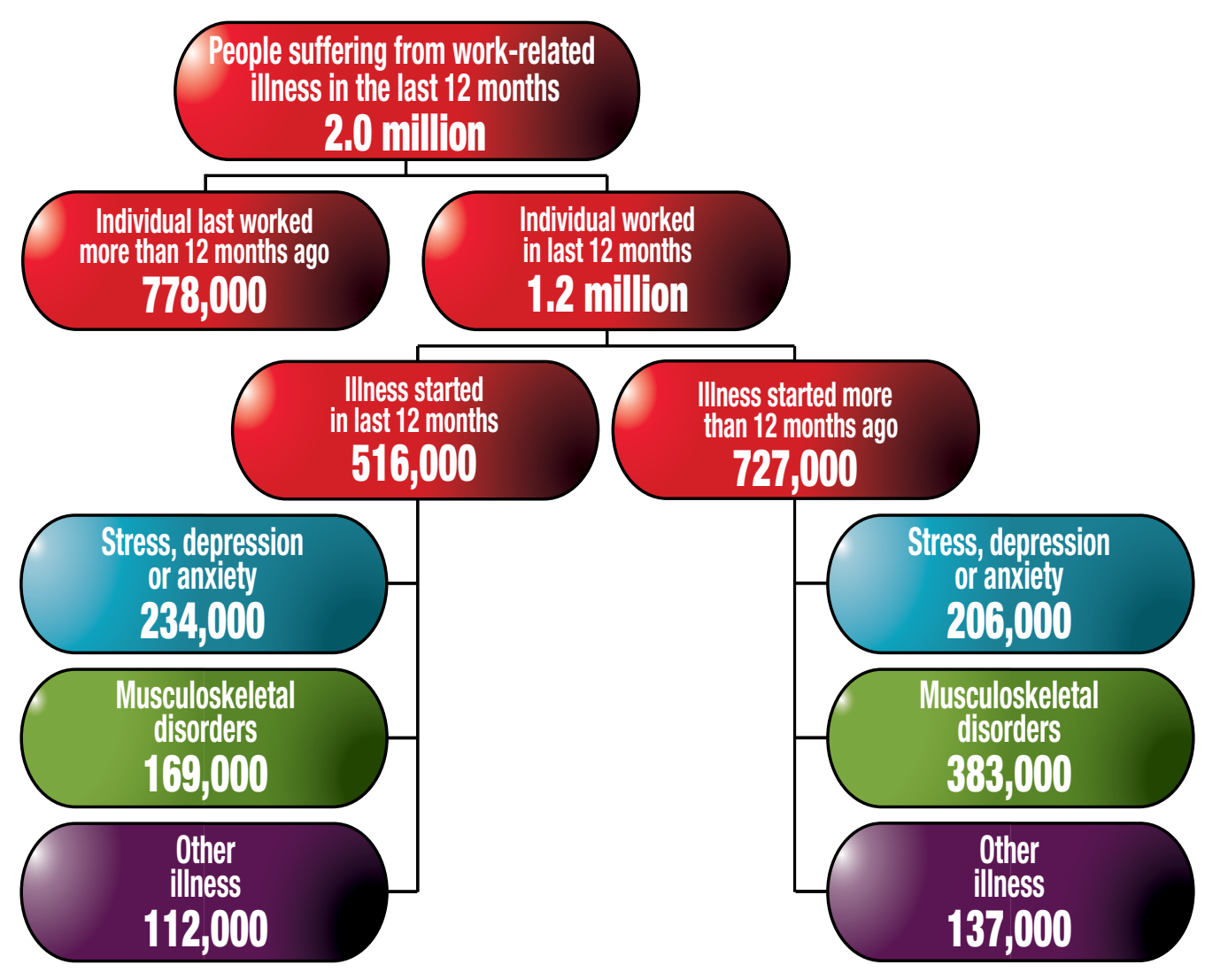

Source: Labour Force Survey

For further information, and detail on earlier years, see www.hse.gov.uk/statistics/fs/swit3w12.x/sx and www.hse.gov.uk/statistics/ffs/swit6w12.xlsx

www.hse.gov.uk/statistics/causdis/index.htm 
Health and Safety Statistics 2014/15

Estimated total and new cases of self-reported work-related illness by type of illness, for people working in the last 12 months

\begin{tabular}{|c|c|c|c|c|c|c|c|}
\hline & & \multicolumn{3}{|c|}{$\begin{array}{l}\text { Total number of cases of work-related } \\
\text { illness in the last } 12 \text { months (thousands) }\end{array}$} & \multicolumn{3}{|c|}{$\begin{array}{l}\text { New cases of work-related } \\
\text { illness in the last } 12 \text { months (thousands) }\end{array}$} \\
\hline & & \multirow[t]{2}{*}{ central } & \multicolumn{2}{|c|}{$95 \%$ Confidence interval } & \multirow[t]{2}{*}{ central } & \multicolumn{2}{|c|}{ 95\% Confidence interval } \\
\hline & & & lower & upper & & lower & upper \\
\hline \multirow[t]{5}{*}{ All illnesses } & $2009 / 10$ & 1276 & 1216 & 1335 & 559 & 520 & 599 \\
\hline & $2010 / 11$ & 1162 & 1102 & 1222 & 497 & 458 & 537 \\
\hline & $2011 / 12$ & 1079 & 1023 & 1135 & 454 & 418 & 491 \\
\hline & $2013 / 14$ & 1244 & 1183 & 1306 & 536 & 495 & 577 \\
\hline & $2014 / 15$ & 1243 & 1180 & 1307 & 516 & 475 & 556 \\
\hline \multirow{5}{*}{$\begin{array}{l}\text { Musculoskeletal } \\
\text { disorders }\end{array}$} & $2009 / 10$ & 576 & 535 & 616 & 191 & 167 & 215 \\
\hline & $2010 / 11$ & 515 & 474 & 555 & 158 & 136 & 181 \\
\hline & $2011 / 12$ & 443 & 408 & 478 & 142 & 121 & 162 \\
\hline & $2013 / 14$ & 526 & 487 & 566 & 184 & 160 & 208 \\
\hline & $2014 / 15$ & 553 & 510 & 595 & 169 & 145 & 193 \\
\hline \multirow{5}{*}{$\begin{array}{l}\text { Stress, } \\
\text { depression } \\
\text { or anxiety }\end{array}$} & $2009 / 10$ & 439 & 405 & 473 & 236 & 211 & 261 \\
\hline & $2010 / 11$ & 402 & 367 & 438 & 213 & 187 & 238 \\
\hline & $2011 / 12$ & 430 & 394 & 466 & 222 & 197 & 247 \\
\hline & $2013 / 14$ & 487 & 449 & 526 & 244 & 216 & 271 \\
\hline & $2014 / 15$ & 440 & 403 & 477 & 234 & 207 & 262 \\
\hline
\end{tabular}

Source: Labour Force Survey.

For further information, and detail on earlier years, see www.hse.gov.uk/statistics//fs/swit3w12.x/sx and www.hse.gov.uk/statistics/lfs/swit6w12.x/sx

2001/02-2013/14 figures have been revised (October 2015), as LFS data sets have been reweighted to reflect population estimates based on the 2011 Census. Note: No ill health data was collected in 2012/13. 


\section{New cases of self-reported work-related illness}

- New cases of ill health have generally fallen since 2001/02, reaching a low of 454,000 in $2011 / 12$. In 2014/15, there were 516,000 new cases of ill health, a similar level to those in $2011 / 12$ and 2013/14 (no data was collected in 2012/13).

- The estimated number of new cases of stress, depression or anxiety has remained broadly flat for more than a decade, with an estimate of 234,000 in the latest year.

- For musculoskeletal disorders, the estimated number of new cases fell from 215,000 in $2001 / 02$ to 142,000 in $2011 / 12$. The level of 169,000 in $2014 / 15$ was similar to those in $2011 / 12$ and $2013 / 14$ (no data was collected in 2012/13).

\section{Estimated new cases of self-reported work-related illness amongst people who worked in the last 12 months}

Note: $95 \%$ confidence interval on average $+/-7 \%$ on the total

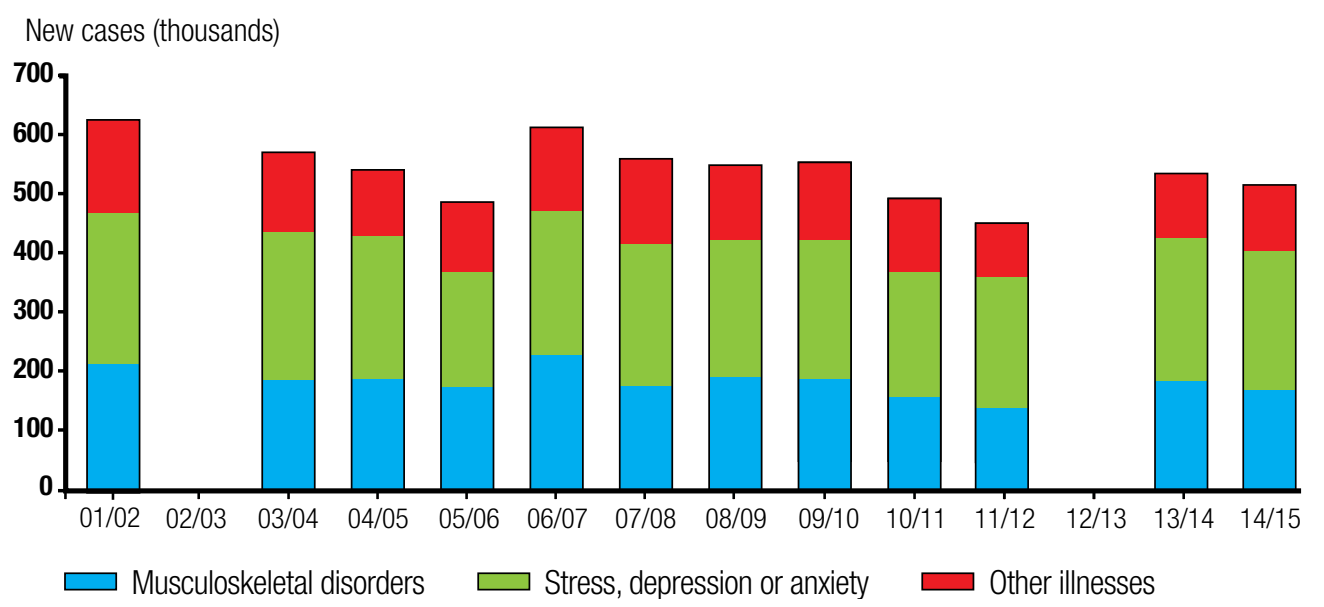

Source: Labour Force Survey

For further information, and detail on earlier years, see www.hse.gov.uk/statistics/fs/swit6w12.x/sx Note: No ill health data was collected in 2002/03 and 2012/13

\section{Change indicator for rates}

of new ill health cases

\section{Since 2013/14}

Since $2009 / 10$

Since $2004 / 05$ 
Reports of ill health by doctors and specialist physicians Since 2005, a surveillance scheme has collected reports of new cases of work-related ill health from a sample of around 250 general practitioners (GPs). In 2014:

- Musculoskeletal disorders (MSDs) were the most common type of work-related illness.

Mental ill health gave rise to most working days lost.

- The distribution of cases was broadly similar to the LFS but with a higher proportion of MSDs, which could partly reflect the inclusion of some injuries reported by GPs and the different perceptions of workattribution between GPs and individual workers.

\section{Comparison between THOR-GP and LFS: proportions of new cases of ill health}

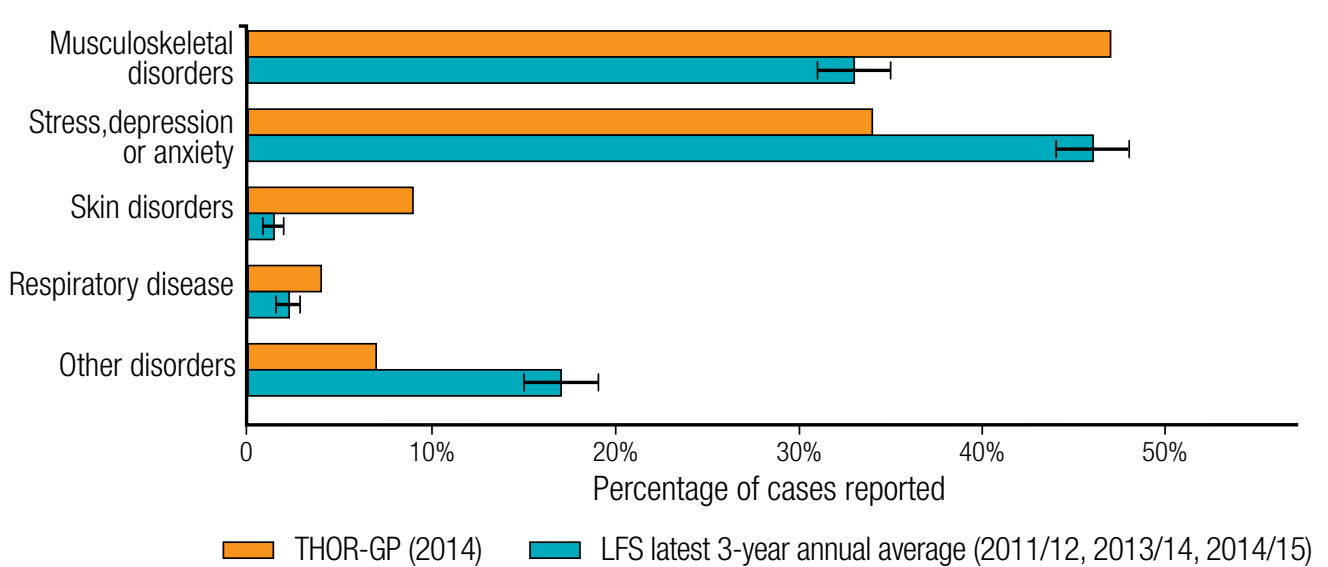

Other surveillance schemes collect reports from specialist physicians on specific types of work-related ill health:

\section{Skin specialists (EPIDERM)}

In 2014, there were an estimated 1,320 new cases of skin disease reported by dermatologists, of which four-fifths were suffering from contact dermatitis.

- Annual cases have fallen over the past 10 years.

Hairdressers/barbers and florists are the occupations with the highest rates of contact dermatitis.

\section{Respiratory specialists (SWORD)}

In 2014, there were an estimated 132 new cases of asthma reported to chest physicians.

- Annual cases have remained broadly constant over the past five years, having fallen in the previous five years.

Vehicle spray painters and bakers are the occupations with the highest rates of asthma. 
III health assessed for Industrial Injuries Disablement Benefit (IIDB)

There were 6,100 new IIDB cases in 2014, of which two-thirds were lung-related diseases.

- In 2009 and 2010 there was an increase in non-lung disease cases solely due to osteoarthritis of the knee in miners and carpet/floor fitters, which was added to the prescribed diseases list in July 2009.

- The next largest categories were vibration white finger, carpal tunnel syndrome and respiratory diseases associated with past exposures to substances such as asbestos and coal dust.

- Apart from asbestos-related disease, the trend in numbers is generally downwards.

Although many diseases in IIDB are prescribed for very specific occupations and/or exposure to specific agents, some diseases are prescribed across a broader range of occupations and exposures, including:

- Asthma - the number of new cases has fallen by two-thirds in the last 10 years (70 in 2014).

- Dermatitis - the number of new cases has fallen from 160 cases in 2004 to 30 cases in 2014.

Deafness - the number of new cases has fallen $60 \%$ in the past 10 years (130 in 2014).
New cases of prescribed diseases (IIDB)

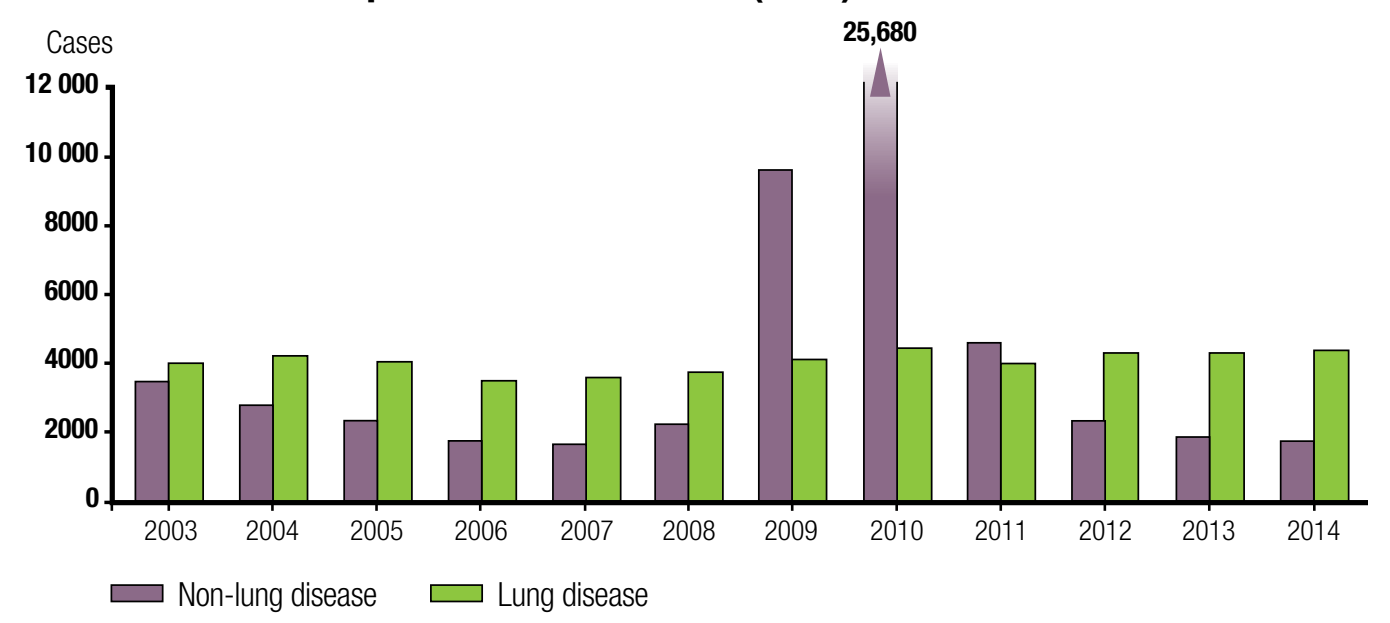

For further information please go to www.hse.gov.uk/statistics/tables/iidb03.x/sx and www.hse.gov.uk/statistics/tables/iidb05.x/sx 


\section{Fatal injuries to workers}

- There were 142 workers fatally injured in 2014/15 (provisional), equivalent to a rate of fatal injury of 0.46 per 100,000 workers.

- The rate for $2014 / 15$ compares to an average rate of 0.53 for the previous five years.

- Over the latest 20-year time period there has been a downward trend in the rate of fatal injury, although more recently (since 2008/09) the trend is less clear.

- Of the main industrial sectors, construction, agriculture, and waste have the highest rates. These sectors accounted for 35,33 , and five fatal injuries to workers, respectively.

\section{Number and rate of fatal injuries to workers}

Number of fatal injuries to workers

Rate of fatal injury (per 100,000 workers)

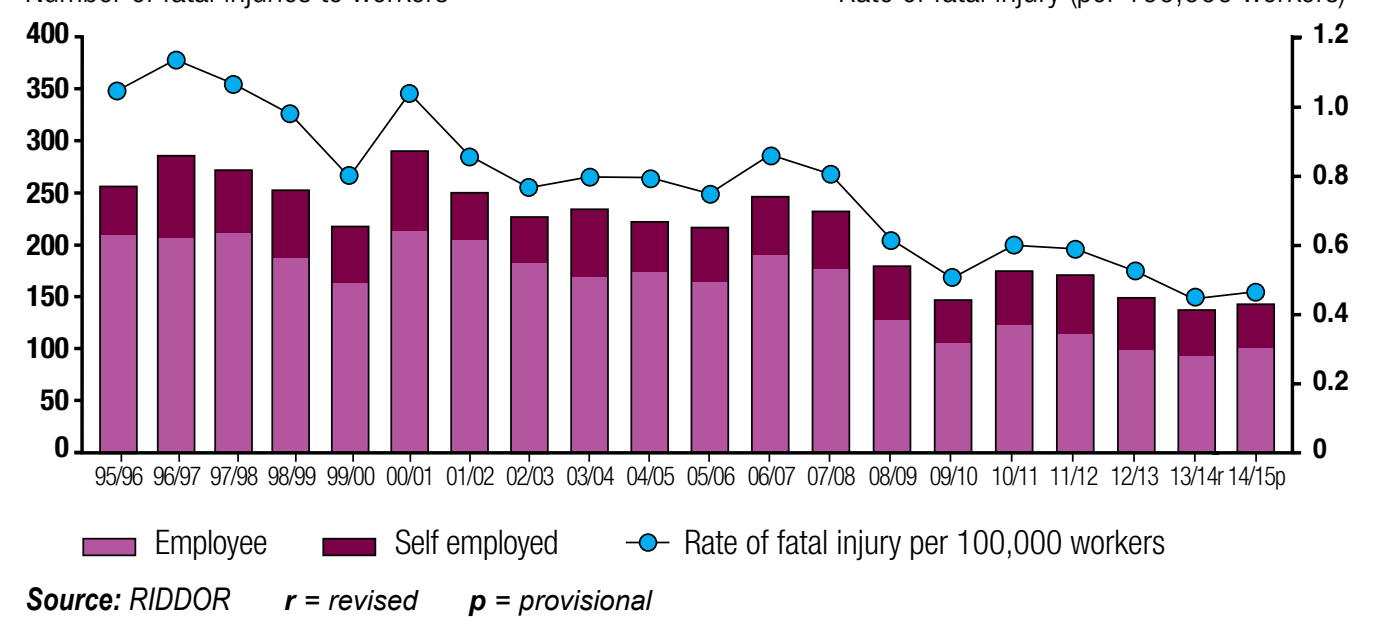

Change indicator for worker fatalities

Since 2013/14

Since 2009/10

Since 2004/05

\begin{tabular}{|c|c|c|c|c|c|c|}
\hline \multirow[t]{2}{*}{ Year } & \multicolumn{2}{|c|}{ Employees } & \multicolumn{2}{|c|}{ Self-employed } & \multicolumn{2}{|r|}{ Workers } \\
\hline & Number & $\begin{array}{c}\text { Rate per } 100,000 \\
\text { employees }\end{array}$ & Number & $\begin{array}{c}\text { Rate per } 100,000 \\
\text { self-employed* }\end{array}$ & Number & $\begin{array}{c}\text { Rate per } 100,000 \\
\text { workers }^{*}\end{array}$ \\
\hline $2010 / 11$ & 122 & 0.49 & 53 & 1.25 & 175 & 0.60 \\
\hline $2011 / 12$ & 114 & 0.45 & 57 & 1.31 & 171 & 0.58 \\
\hline $2012 / 13$ & 99 & 0.39 & 51 & 1.13 & 150 & 0.50 \\
\hline $2013 / 14 r$ & 92 & 0.36 & 44 & 0.96 & 136 & 0.45 \\
\hline $2014 / 15 p$ & 99 & 0.38 & 43 & 0.89 & 142 & 0.46 \\
\hline $\begin{array}{l}\text { Five-year average } \\
(2009 / 10-2013 / 14 r)\end{array}$ & 106 & 0.42 & 50 & 1.14 & 156 & 0.53 \\
\hline
\end{tabular}

*2009/10 - 2013/14 rates have been revised (October 2015) as employment datasets have been reweighted to reflect population estimates based on the 2011 Census. 


\section{Employer-reported non-fatal injuries}

- For non-fatal injuries reported by employers under RIDDOR, analysis of the trend in the rate is complicated by changes in the reporting regulations over recent years. Allowing for these changes, there may be signs the downward trend over the past

10 years is slowing down.

- There were 76,054 non-fatal injuries to employees reported in $2014 / 15$ (provisional). Of these injuries, the most common kinds of accident were caused by slips and trips $(28 \%)$, handling, lifting or carrying (23\%), and being struck by moving objects (10\%).

- Non-fatal injury notifications from employers are substantially underreported, with current levels of reporting estimated at below half.

\section{Employer-reported non-fatal injuries to employees}

Number of non-fatal injuries to employees

200000

180000

160000 .

140000

120000

100000

80000

60000

40000

20000

0

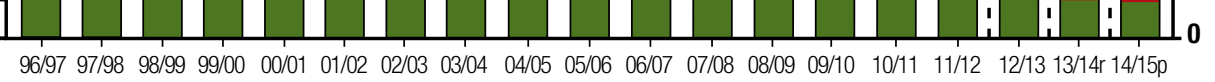

$\square$ Major or specified

Over-7-day injury

$\square$ Over-3-day injury

-o- Non-fatal injury rate (major plus over-3-day)

$\triangle$ Non-fatal injury rate (from 12/13 major plus over-7-day; during 13/14r,

major or specified plus over-7-day, from 14/15p, specified plus over-7-day)

- - - - Series break (change to over-7-day from 12/13 and specified injury during 13/14r)

Rate of non-fatal injury (per 100,000 employees)

-800
-700
600
-500
-400
-300
-200
100
0
$-3-$ day)
$4 r$,
$-7-$ day)

Change indicator for reported non-fatal injuries

\section{Since 2013/14 n/a}

Since 2009/10

Since $2004 / 05$

\begin{tabular}{c|c|c|c|c|} 
Year & $\begin{array}{c}\text { Number of major/specified } \\
\text { injuries to employees }\end{array}$ & $\begin{array}{c}\text { Number of over-3-day/over- } \\
7 \text {-day injuries to employees }\end{array}$ & $\begin{array}{c}\text { Total number of non-fatal } \\
\text { injuries to employees }\end{array}$ & $\begin{array}{c}\text { Rate of non-fatal injury } \\
\text { (per } 100,000 \text { employees) }\end{array}$ \\
\hline $\mathbf{2 0 1 0 / 1 1}$ & 24,944 & 91,742 & 116,686 & 464.4 \\
$\mathbf{2 0 1 1 / 1 2}$ & 22,094 & 89,205 & 111,299 & 442.6 \\
$\mathbf{2 0 1 2 / 1 3}$ & 20,214 & 60,154 & 80,368 & 318.4 \\
$\mathbf{2 0 1 3 / 1 4 r}$ & 19,118 & 59,553 & 78,671 & 307.4 \\
$\mathbf{2 0 1 4 / 1 5 p}$ & 18,084 & 57,970 & 76,054 & 292.9
\end{tabular}

*2010/11 - 2013/14 rates have been revised (October 2015) as employment datasets have been reweighted to reflect population estimates based on the 2011 Census. 


\section{Self-reported injuries}

- Self-reported non-fatal injuries at work have generally followed a downward trend over the last ten years or so, but show signs of levelling off in recent years.

- Around a quarter of non-fatal injuries have resulted in over-7-days absence from work and around a third in over-3-days.

- In 2014/15, an estimated 611,000 workers sustained a non-fatal injury at work. Of these injuries, 198,000 led to over-3-days absence from work and 152,000 led to over-7-days absence.
Estimated cases of self-reported non-fatal injury amongst people who worked in the last 12 months, by absence duration

Note: $95 \%$ confidence interval on average $+/-6 \%$ on the total

Cases (thousands)

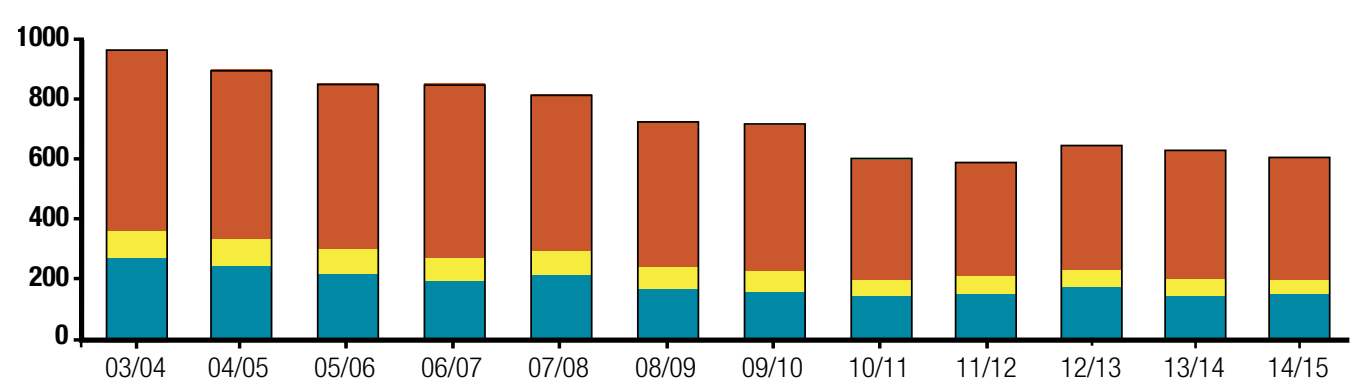

$\square$ Less than 4 days $\square$ Between 4 and 7 days $\square$ 0ver-7-days Non-fatal injury cases (thousands)

\begin{tabular}{|c|c|c|c|c|c|c|c|c|c|}
\hline \multirow[b]{4}{*}{ Year } & \multicolumn{9}{|c|}{ Non-fatal injury cases (thousands) } \\
\hline & \multicolumn{3}{|c|}{ All injury } & \multicolumn{3}{|c|}{ Over-3-day absence } & \multicolumn{3}{|c|}{ Over-7-day absence } \\
\hline & \multirow[t]{2}{*}{ central } & \multicolumn{2}{|c|}{$95 \%$ Confidence interval } & \multirow[t]{2}{*}{ central } & \multicolumn{2}{|c|}{$95 \%$ Confidence interval } & \multirow[t]{2}{*}{ central } & \multicolumn{2}{|c|}{ 95\% Confidence interval } \\
\hline & & lower & upper & & lower & upper & & lower & upper \\
\hline $2009 / 10$ & 726 & 681 & 772 & 232 & 207 & 258 & 165 & 144 & 186 \\
\hline 2010/11 & 605 & 561 & 649 & 201 & 176 & 225 & 151 & 129 & 172 \\
\hline 2011/12 & 594 & 551 & 636 & 214 & 189 & 240 & 158 & 135 & 180 \\
\hline $2012 / 13$ & 647 & 601 & 693 & 232 & 204 & 259 & 176 & 152 & 200 \\
\hline $2013 / 14$ & 631 & 584 & 677 & 203 & 177 & 228 & 148 & 127 & 169 \\
\hline $2014 / 15$ & 611 & 566 & 656 & 198 & 173 & 223 & 152 & 130 & 173 \\
\hline
\end{tabular}

Source: Labour Force Survey.

For further information, and detail on earlier years, see www.hse.gov.uk/statistics/lfs/lfsinj1.x/sx and www.hse.gov.uk/statistics/lfs/injtme.x/sx 2001/02-2013/14 figures have been revised (October 2015), as LFS data sets have been reweighted to reflect population estimates based on the 2011 Census. 
Rate of total cases of ill health per 100,000 people employed in the last 12 months, three-year average 2014/15 (LFS)

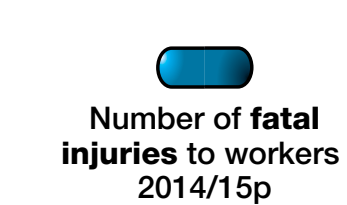
Rate of non-fatal injury per 100,000 workers, three-year average $2012 / 13$ to 2014/15 (LFS)
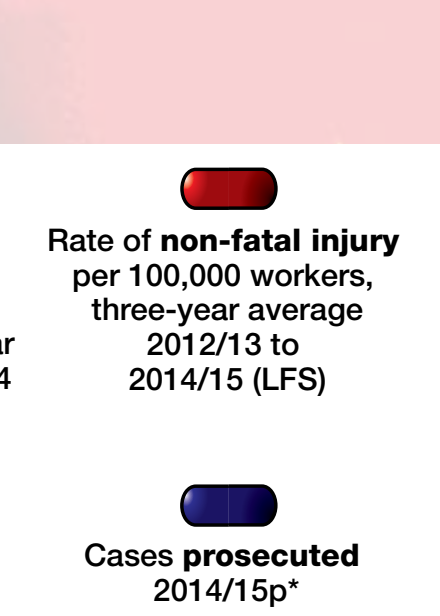
2014/15p $2014 / 15 p^{\star}$
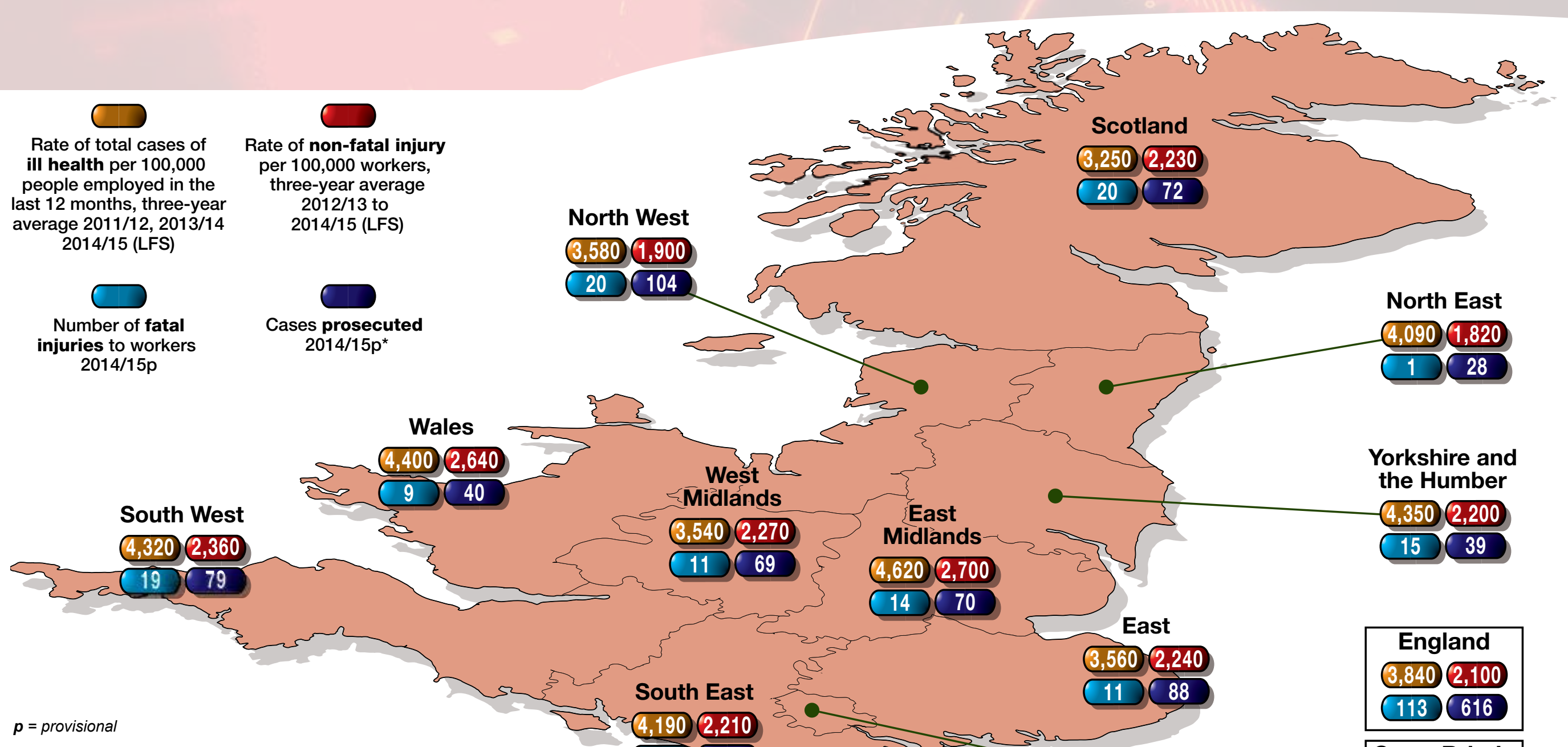

$\boldsymbol{p}=$ provisional

Notes: Labour Force Survey (LFS) rates relate to place of residence, fatality data relates to place of work and prosecution data relates to the location of the court where the case was heard

* Cases prosecuted by HSE, Local Authorities, and in Scotland, the Crown Office and Procurator Fiscal Service.

\section{North West}

$3,5 8 0 \longdiv { 1 , 9 0 0 }$ 20104

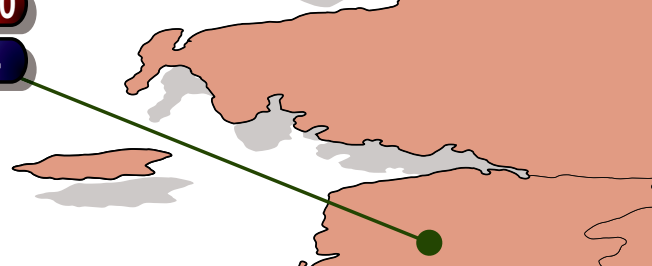
象
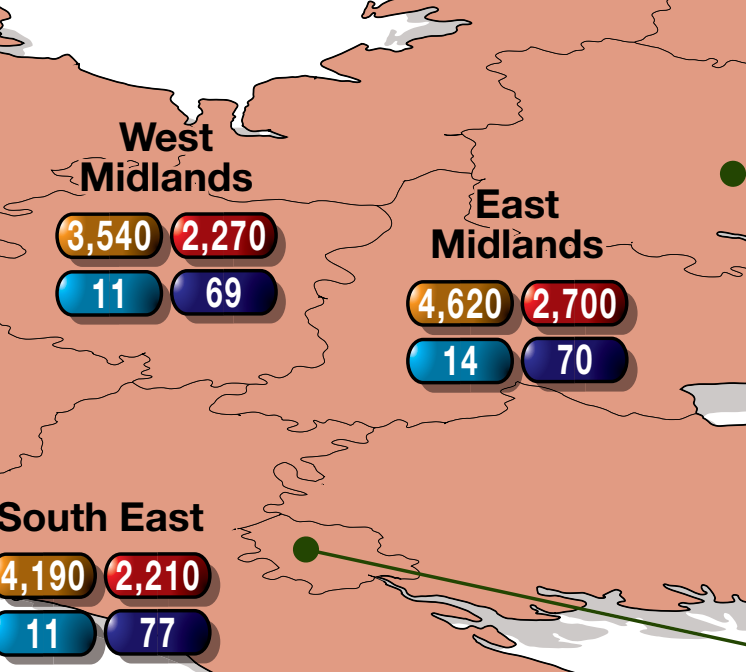

Scotland

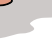

\section{England $3,8 4 0 \longdiv { 2 , 1 0 0 }$ $1 1 3 \longdiv { 6 1 6 }$}

Great Britain $3,820,2,140$ 142728

Yorkshire and

4,350 2,200

1539

$2,9 7 0 \longdiv { 1 . 4 7 0 }$ 
. SOURCES AND DEFINITIONS

\section{Self-reported illness and injuries by industrial sector}

- Industry sectors with ill health rates statistically significantly higher than the rate for all industries were public administration and defence, and human health and social work activities.

- For injuries, agriculture, forestry and fishing, construction, accommodation and food service activities, transport and storage, and manufacturing had statistically significantly higher rates than for all industries.

\section{Estimated rates of total cases of self-reported work-related illness and non-fatal injury, by industry, for people working in the last 12 months, three-year average\#}

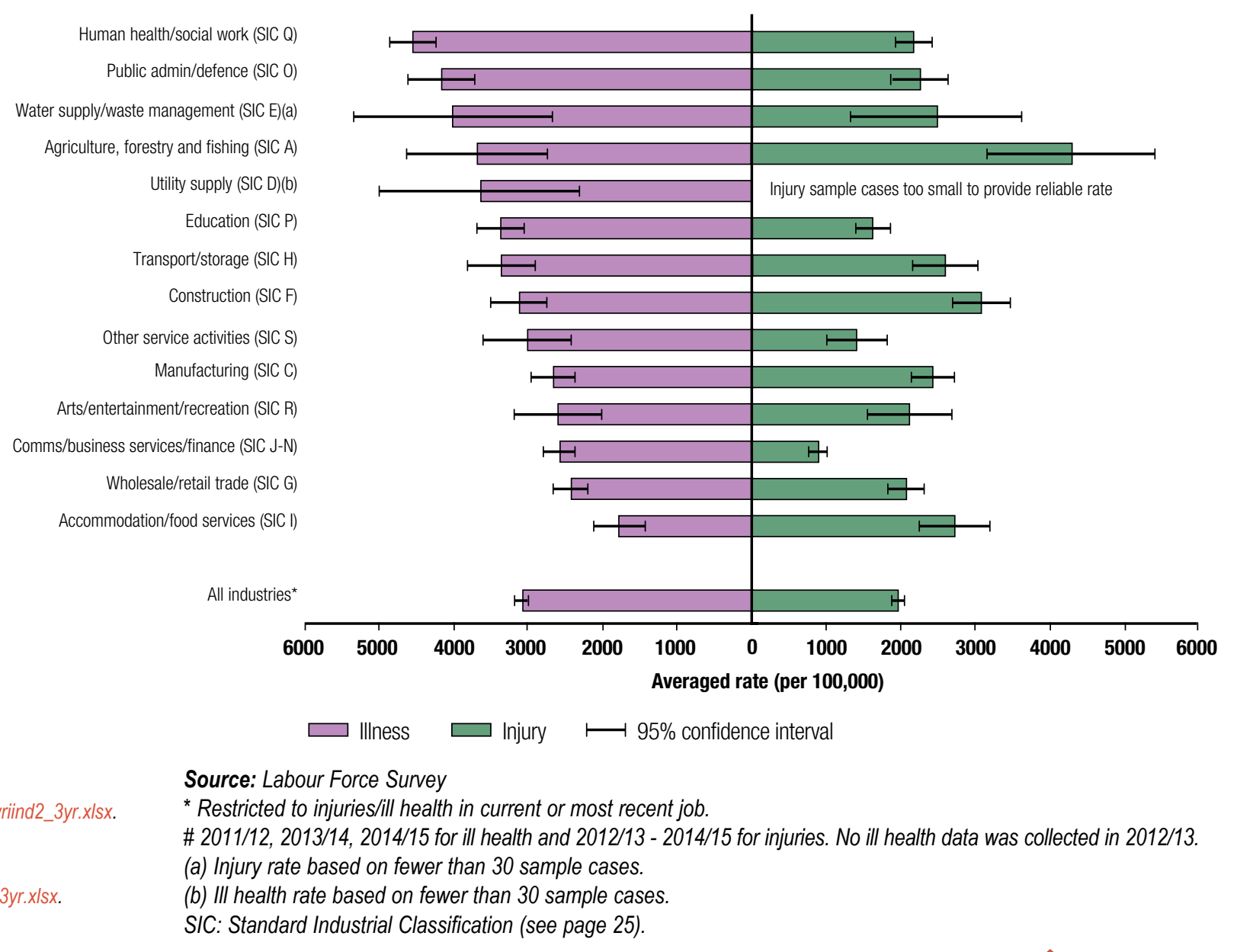

III health - further information

For further information on total cases of ill health, and detail on earlier years, see www.hse.gov.uk/statistics/fs/wriind2 3yr.xlsx. Sample numbers are too small to provide reliable rates for Extraction (SIC B).

Injuries - further information

For further information on non-fatal injuries, and detail on earlier years see www.hse.gov.uk/statistics/Ifs/injind3_3yr.x/sx. Sample numbers are too small to provide reliable rates for Extraction (SIC B). 
Health and Safety Statistics 2014/15

Estimated rates of total cases of self-reported work-related illness and

\section{Self-reported illness and injuries by occupation}

Workers in skilled trade occupations and care, leisure and other personal service occupations have statistically significantly higher rates of both injury and ill health compared to all occupations.

- Professional occupations has a statistically significantly higher rate for ill health, but relatively low injury rate.

- Process, plant and machine operatives, and elementary occupations have injury rates which are statistically significantly higher than the average.

\section{non-fatal injury, by occupation, for people working in the last 12 months,} three-year average\#

Skilled trades (SOC 5)

Caring/leisure/other service (SOC 6)

Professional (SOC 2)

Associate professional/technical (SOC 3)

Process/plant/machine operatives (SOC 8)

Managers/directors/senior officials (SOC 1)

Elementary (SOC 9)

Sales/customer service (SOC 7)

Administrative/secretarial (SOC 4)

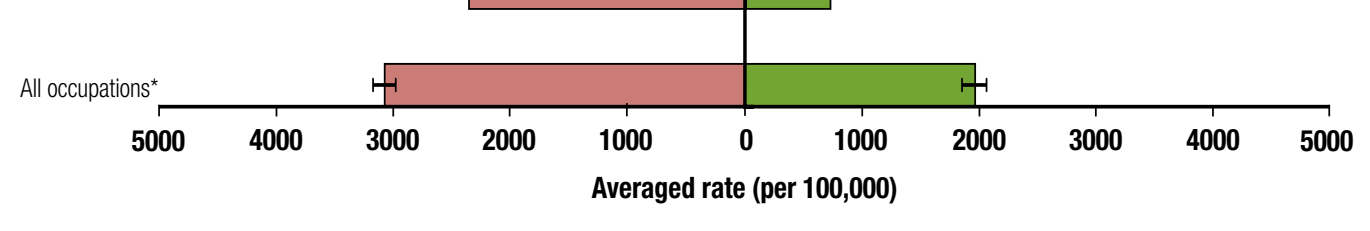

$\square$ Illness $\square$ Injury $\longmapsto 95 \%$ confidence interval

Source: Labour Force Survey

* Restricted to injuries/ill health in current or most recent job.

\# 2010/11, 2013/14, 2014/15 for ill health and 2012/13 - 2014/15 for injuries. No ill health data was collected in 2012/13. SOC: Standard Occupational Classification (see page 26).

III health - further information

For further information on total cases of ill health, and detail on earlier years, see www.hse.gov.uk/statistics/fs/wriocc2 3yr.xlsx

Injuries - further information

For further information on non-fatal injuries, and detail on earlier years see www.hse.gov.uk/statistics/fs/injocc3_3yr.xlsx 


\section{Workplace risks}

Work activity can present both physical and psychosocial risk factors.

- A 2014 national survey of workplaces employing 5 or more employees asked about the presence of selected physical and psychosocial risk factors in the workplace.

- The most commonly cited risk factor across all workplaces was 'Dealing with difficult customers, patients, pupils etc.', present in about two-thirds of workplaces with 5 or more employees. While a recognised psychosocial risk, it can also present as a physical risk in terms of threats and violent incidents towards workers.

- 'Lifting or moving people or loads' was the second most prevalent reported risk factor in workplaces (present in just under $60 \%$ of workplaces with 5 or more employees). When this risk is not adequately controlled it leads to the potential for manual handling accidents and longer-term musculoskeletal disorders.

- Other physical risk factors present in the workplace that contribute to musculoskeletal disorders include 'repetitive hand or arm movements', 'slips, trips and falls' and 'working in tiring or painful positions'. Each of these risks was reported to be present in around half of all workplaces with 5 or more employees.

\section{Estimated percentage of workplaces where various risks} are reported to be present

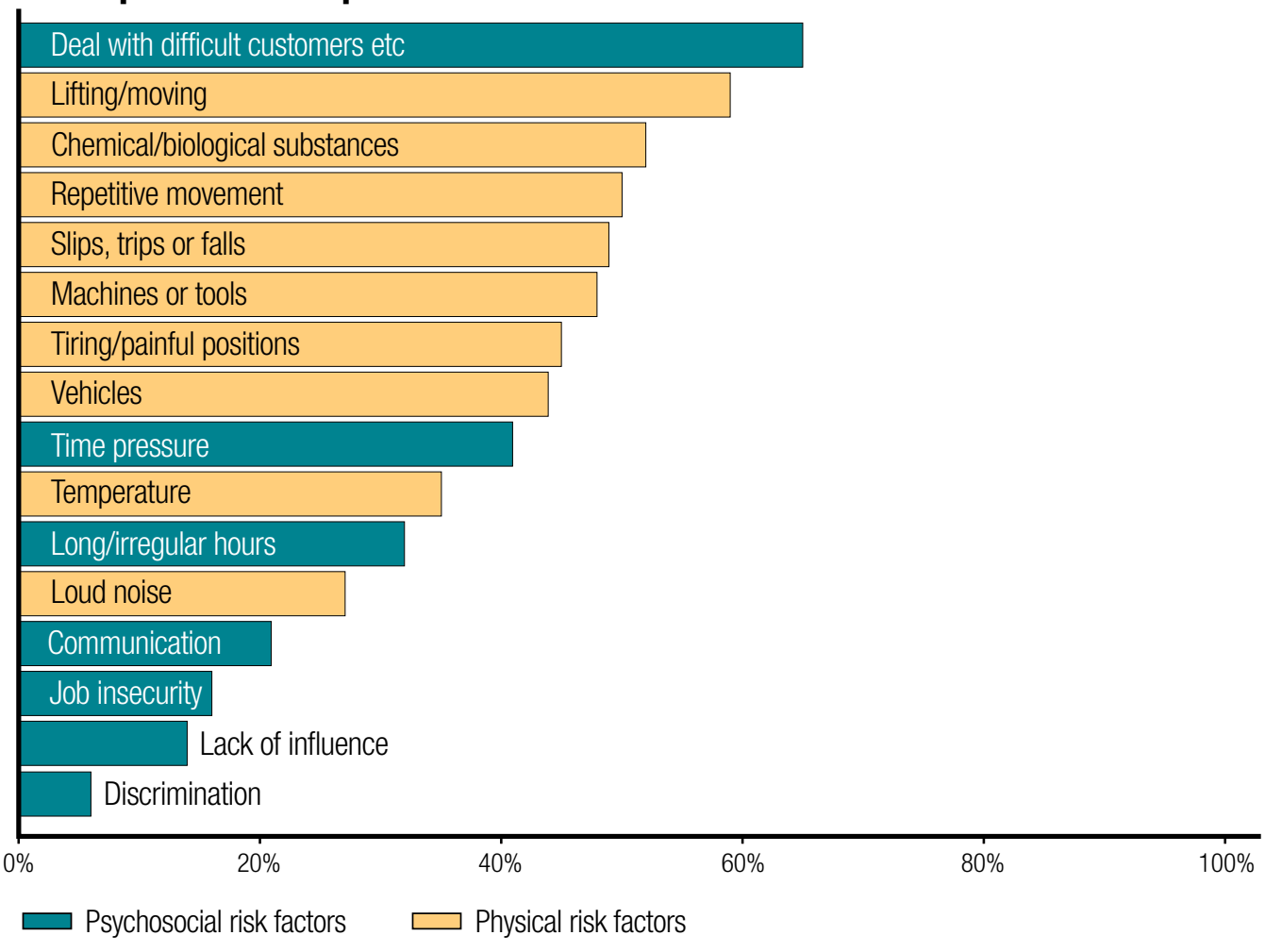

Source: ESENER, 2014 


\section{European Comparisons}

Health and safety systems differ across Europe in recording, reporting and enforcement; however, some data is available allowing for a comparison of UK performance on health and safety measures and outcomes against other large economies and the EU in general.

Overall, UK performance is better than many other European countries in key outcome areas, and in health and safety management.

In 2012, the standardised rate of fatal injuries in the UK was amongst the lowest of those published by Eurostat. The UK performs consistently well compared to other large economies such as Germany, France, Italy, Spain and Poland, as well as compared to the EU average.

- Non-fatal injuries in the UK were at a similar level to other large economies in 2013, while rates of work-related ill health resulting in sick leave were lower than most other EU countries.

- The UK is one of the better performing EU countries in terms of percentage of establishments who conducted a regular risk assessment.

\begin{tabular}{l|l|l|} 
& $\begin{array}{c}\text { Peers } \\
\text { France, Italy, Spain, } \\
\text { Poland, Germany }\end{array}$ & EU-28 \\
\hline $\begin{array}{l}\text { Fatalities - standardised incidence rate } \\
\text { per } 100000 \text { employed (Eurostat, 2012) }\end{array}$ & & \\
\hline $\begin{array}{l}\text { Self-reported work-related injuries } \\
\text { resulting in sick leave (LFS, 2013)* }\end{array}$ & & \\
\hline $\begin{array}{l}\text { Self-reported work-related health problems } \\
\text { resulting in sick leave (LFS, 2013)* }\end{array}$ & & \\
\hline $\begin{array}{l}\text { Establishments regularly conducting } \\
\text { workplace risk assessments (ESENER, 2014) }\end{array}$ & & \\
\hline
\end{tabular}

* Methodological problems mean that Germany is excluded from LFS comparisons, and as a result a figure for EU-28 is not available for these measures.

\begin{tabular}{|l|l|}
\hline \multicolumn{2}{|c|}{ Key } \\
\hline $\begin{array}{l}\text { GB performance better than comparators } \\
\text { Comparison not available }\end{array}$ & GB performance in line with comparators \\
& GB performance worse than comparators \\
\hline
\end{tabular}




\section{Self-reported working days lost}

- The total number of working days lost has generally followed a downward trend since 2000-02, but shows signs of levelling off in recent years.

The estimated number of working days lost has fallen from 39.5 million in 2000-02 to 27.3 million in 2014/15.

- In 2014/15, 23.3 million days were lost due to work-related ill health and 4.1 million due to workplace injuries.

- On average, each person suffering took around 15 days off work, 19 days for ill health cases and 6.7 for injuries.

- Stress, depression or anxiety and musculoskeletal disorders accounted for the majority of days lost due to work-related ill health, 9.9 and 9.5 million days respectively.

- The average days lost per case for stress, depression or anxiety (23 days) was higher than for musculoskeletal disorders (17 days).

\section{Estimated working days lost due to work-related incidents}

Note: $95 \%$ confidence interval on average $+/-9 \%$ on the total

Days lost (millions)

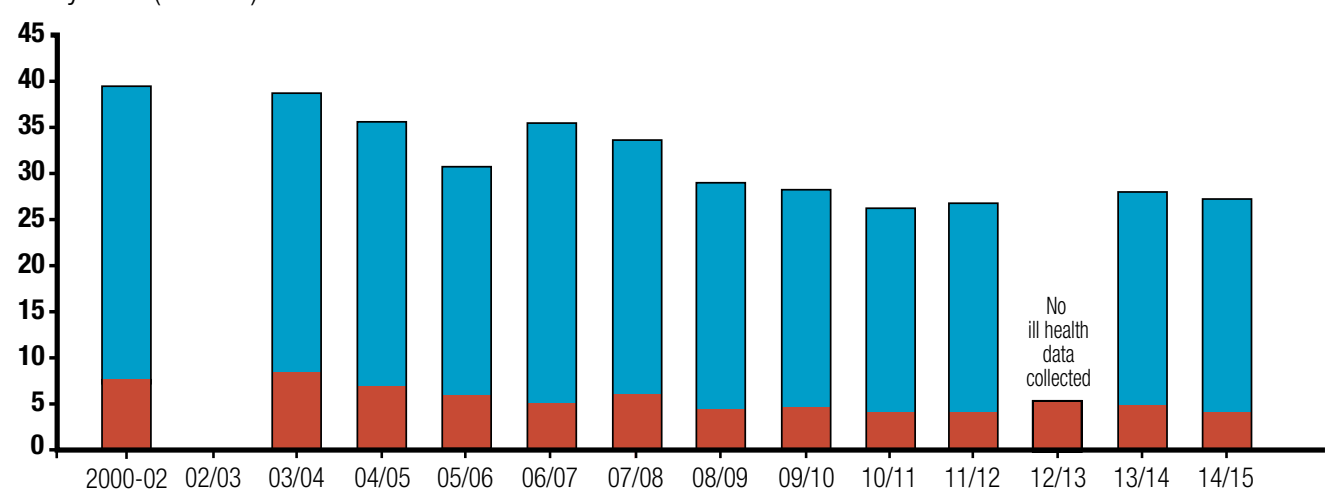

$\square$ Due to workplace injury

$\square$ Due to work-related illness

\section{Source: Labour Force Survey}

For further information see www.hse.gov.uk/statistics/lfs/swit1.x/sx.

Notes: No data on working days lost was collected in 2002/03, and only data for injuries in 2012/13. 2000-02 refers to 2000/01 injury data and 2001/02 illness data combined.

\section{Change indicator for}

days lost per worker

\begin{tabular}{l} 
Since 2013/14 \\
\hline Since 2009/10 \\
\hline Since 2004/05
\end{tabular}


Health and Safety Statistics 2014/15

Estimated working days lost and associated average days lost per case and per worker due to self-reported work-related illness or workplace injuries

\begin{tabular}{|c|c|c|c|c|c|c|c|c|c|c|}
\hline & \multirow[b]{3}{*}{ Year } & \multicolumn{3}{|c|}{ Estimated days lost (thousands) } & \multicolumn{3}{|c|}{ Average days lost per case* } & \multicolumn{3}{|c|}{ Average days lost per worker } \\
\hline & & \multirow[t]{2}{*}{ central } & \multicolumn{2}{|c|}{$95 \%$ Confidence interval } & \multirow[t]{2}{*}{ central } & \multicolumn{2}{|c|}{ 95\% Confidence interval } & \multirow[t]{2}{*}{ central } & \multicolumn{2}{|c|}{ 95\% Confidence interval } \\
\hline & & & lower & upper & & lower & upper & & lower & upper \\
\hline \multirow[t]{4}{*}{ All illnesses } & $2010 / 11$ & 21,393 & 18,852 & 23,934 & 18.4 & 16.4 & 20.4 & 0.91 & 0.80 & 1.01 \\
\hline & 2011/12 & 22,202 & 19,604 & 24,800 & 20.6 & 18.4 & 22.8 & 0.94 & 0.83 & 1.05 \\
\hline & 2013/14 & 23,602 & 20,919 & 26,285 & 19.0 & 17.0 & 20.9 & 0.96 & 0.85 & 1.07 \\
\hline & 2014/15 & 23,271 & 20,601 & 25,941 & 18.7 & 16.8 & 20.7 & 0.93 & 0.82 & 1.03 \\
\hline \multirow[t]{5}{*}{ All injuries } & $2010 / 11$ & 4,503 & 3,576 & 5,431 & 7.4 & 6.0 & 8.9 & 0.19 & 0.15 & 0.23 \\
\hline & $2011 / 12$ & 4,533 & 3,658 & 5,408 & 7.6 & 6.3 & 9.0 & 0.19 & 0.16 & 0.23 \\
\hline & $2012 / 13$ & 5,184 & 4,166 & 6,202 & 8.0 & 6.5 & 9.5 & 0.22 & 0.17 & 0.26 \\
\hline & $2013 / 14$ & 4,447 & 3,512 & 5,381 & 7.1 & 5.7 & 8.5 & 0.18 & 0.14 & 0.22 \\
\hline & $2014 / 15$ & 4,075 & 3,330 & 4,820 & 6.7 & 5.5 & 7.8 & 0.16 & 0.13 & 0.19 \\
\hline \multirow{4}{*}{$\begin{array}{l}\text { All illnesses } \\
\text { and injuries }\end{array}$} & $2010 / 11$ & 25,896 & 23,163 & 28,629 & 15.1 & 13.6 & 16.5 & 1.10 & 0.98 & 1.21 \\
\hline & $2011 / 12$ & 26,735 & 23,950 & 29,519 & 16.6 & 15.0 & 18.1 & 1.13 & 1.02 & 1.25 \\
\hline & $2013 / 14$ & 28,048 & 25,189 & 30,908 & 15.5 & 14.0 & 16.9 & 1.14 & 1.02 & 1.26 \\
\hline & $2014 / 15$ & 27,346 & 24,486 & 30,207 & 15.2 & 13.8 & 16.7 & 1.09 & 0.97 & 1.20 \\
\hline
\end{tabular}

Source: Labour Force Survey

* "case" refers to persons suffering from a workplace injury or a work-related illness.

For further information, and detail on earlier years, see www.hse.gov.uk/statistics/lfs/swit1.x/sx.

2001/02-2013/14 figures have been revised (October 2015), as LFS data sets have been reweighted to reflect population estimates based on the 2011 Census

Note: No ill health data was collected in 2012/13. 


\section{Economic costs to Britain}

Workplace injuries and ill health impose both financial costs (for example, in terms of lost production) and human costs (in terms of the impact on an individual's quality of life and for fatal injuries, loss of life). The total economic cost of workplace injuries and ill health includes both the financial costs incurred and a valuation of the human costs.

- In 2013/14, injuries and new cases of ill health in workers resulting largely from current working conditions* cost society an estimated $£ 14.3$ billion; $£ 9.4$ billion from illness, $£ 4.9$ billion from injury.

- The estimated cost has generally fallen over the last 10 years, but shows signs of levelling off more recently. This reduction is driven by falls in injury costs, with illness costs showing no overall trend.

- The majority of costs fall on individuals (57\%), while employers and government/taxpayers each bear a similar proportion (19\% and $24 \%$ respectively).

* HSE will be publishing a separate estimate of costs of work-related cancer, which largely result from historic working conditions, towards the end of 2015.

\section{Change indicator for Costs to Britain}

Since 2009/10

Since 2004/05

Costs to Britain of workplace injury and new cases of work-related ill health (2013 prices)

Note: $95 \%$ confidence interval on average $+/-7 \%$ on the total

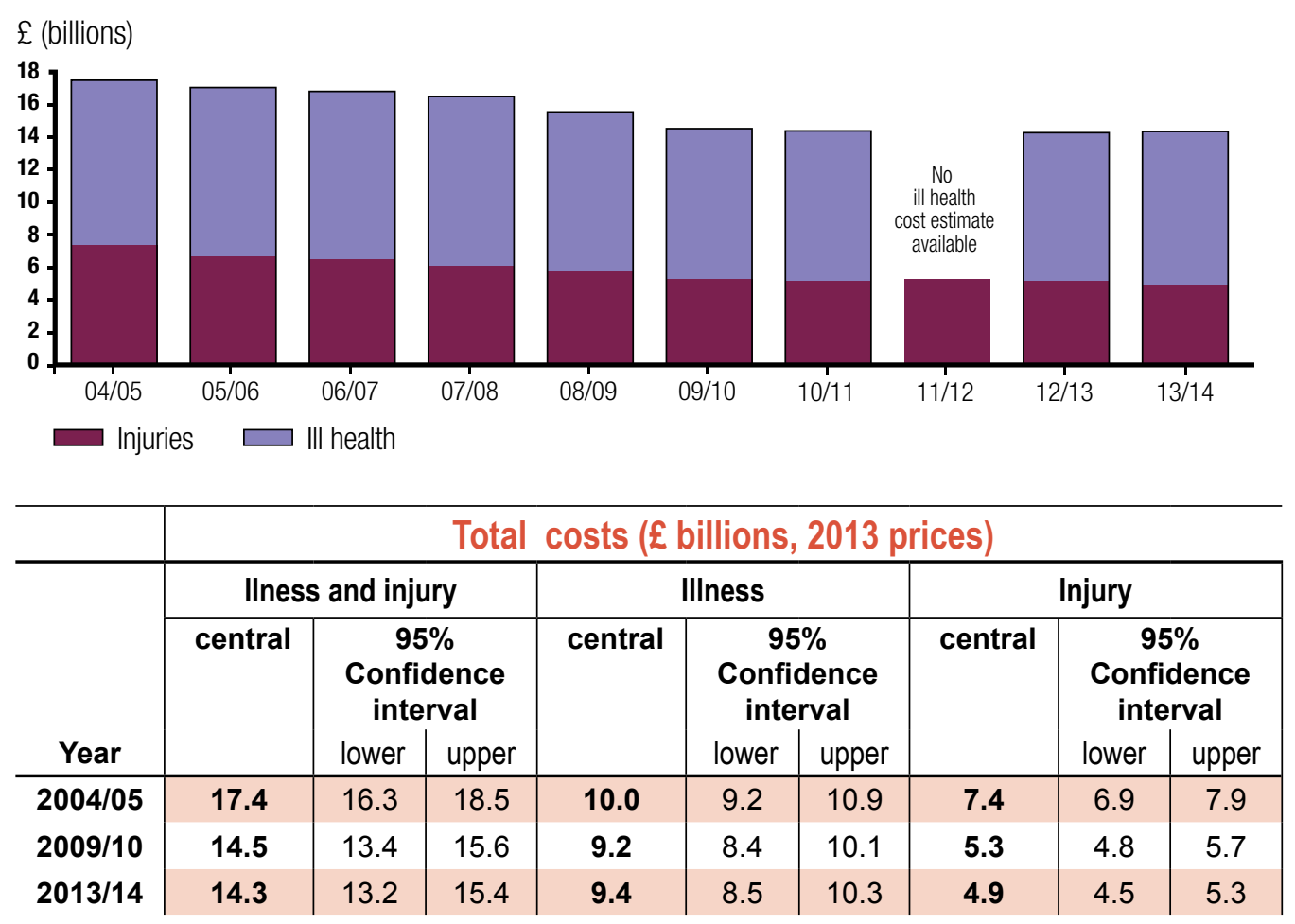

Source: HSE Costs to Britain model 
Cases instituted by HSE, local authorities and, in Scotland, the Crown Office and Procurator Fiscal Service*

- Across Great Britain, 728 cases were prosecuted for health and safety breaches in 2014/15p (including cases where multiple offences were brought).

- These cases led to 682 convictions for at least one offence, a conviction rate of $94 \%$, and total fines received of $£ 19 \mathrm{~m}$.

- Of these 728 cases:

- HSE prosecuted 586 cases in England and Wales, an increase of $2 \%$ from the previous year, and secured 544 convictions $(93 \%)$.

- Local authorities prosecuted 70 cases in England and Wales, a decrease of $20 \%$ from the previous year, and secured 68 convictions (97\%).

- The Procurator Fiscal heard 72 cases in Scotland, a rise of $49 \%$ on the previous year, and secured 70 convictions (97\%).

\section{Change indicator for \\ cases prosecuted}

Since 2013/14

Since 2009/10

Since 2004/05 $\mathrm{n} / \mathrm{a}$

* In Scotland HSE and local authorities investigate potential offences but cannot institute legal proceedings. HSE and local authorities send a report to the Crown Office and Procurator Fiscal Service (COPFS). COPFS makes the final decision whether to institute legal proceedings and which offences are taken. For more information, please see www.hse.gov.uk/statistics/sources.pdf

\section{Prosecution cases resulting in at least one conviction}

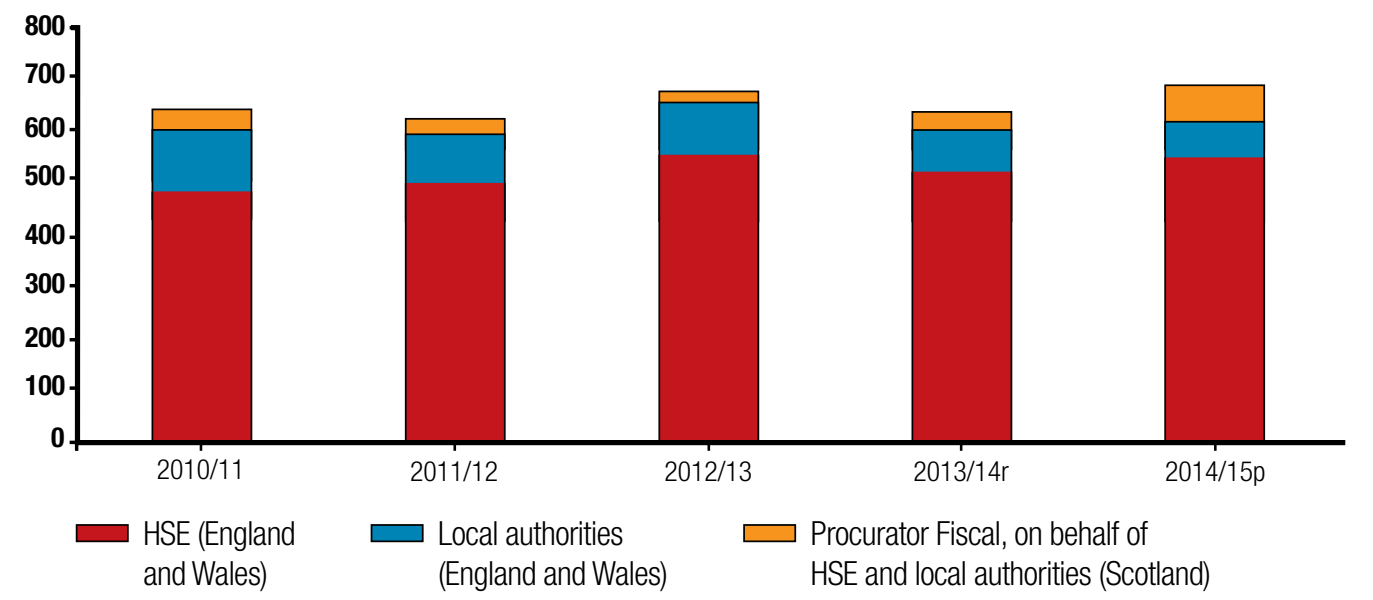

For further information, please go to www.hse.gov.uk/statistics/tables/ef1.xlsx

\begin{tabular}{|c|c|c|c|c|}
\hline & & $\begin{array}{l}\text { HSE } \\
\text { (England and } \\
\text { Wales) }\end{array}$ & $\begin{array}{l}\text { Local authorities } \\
\text { (England and } \\
\text { Wales) }\end{array}$ & $\begin{array}{l}\text { Procurator Fiscal, on behalf } \\
\text { of HSE and local authorities } \\
\text { (Scotland) }\end{array}$ \\
\hline \multirow{5}{*}{$\begin{array}{l}\text { Cases } \\
\text { resulting } \\
\text { in at } \\
\text { least one } \\
\text { conviction }\end{array}$} & $2010 / 11$ & 482 & 120 & 38 \\
\hline & $2011 / 12$ & 499 & 94 & 33 \\
\hline & $2012 / 13$ & 553 & 100 & 26 \\
\hline & $2013 / 14 r$ & 535 & 85 & 36 \\
\hline & $2014 / 15 p$ & 544 & 68 & 70 \\
\hline
\end{tabular}

$r=$ revised $\quad p=$ provisional 
Offences prosecuted by HSE, local authorities and, in Scotland, the Crown Office and Procurator Fiscal Service*

- Over the 728 prosecution cases heard in Great Britain in 2014/15p, there were 1,211 offences prosecuted. Of these, 1,047 offences resulted in a conviction, a rate of $86 \%$.

- Out of the 1,211 offences prosecuted:

- HSE prosecuted 979 offences in England and Wales, similar to the previous year, and secured 836 convictions (85\%).

- Local authorities prosecuted 142 offences in England and Wales, a decrease of $26 \%$ from the previous year, and secured 131 convictions (92\%).

- The Procurator Fiscal heard 90 offences in Scotland, an increase of $105 \%$, and secured 80 convictions (89\%).

Change indicator for

breaches prosecuted

\begin{tabular}{l} 
Since 2013/14 \\
\hline Since 2009/10 \\
\hline Since 2004/05 \\
\hline
\end{tabular}

* In Scotland HSE and local authorities investigate potential offences but cannot institute legal proceedings. HSE and local authorities send a report to the Crown Office and Procurator Fiscal Service (COPFS). COPFS makes the final decision whether to institute legal proceedings and which offences are taken. For more information, please see www.hse.gov.uk/statistics/sources.pdf

\section{Prosecution offences instituted}

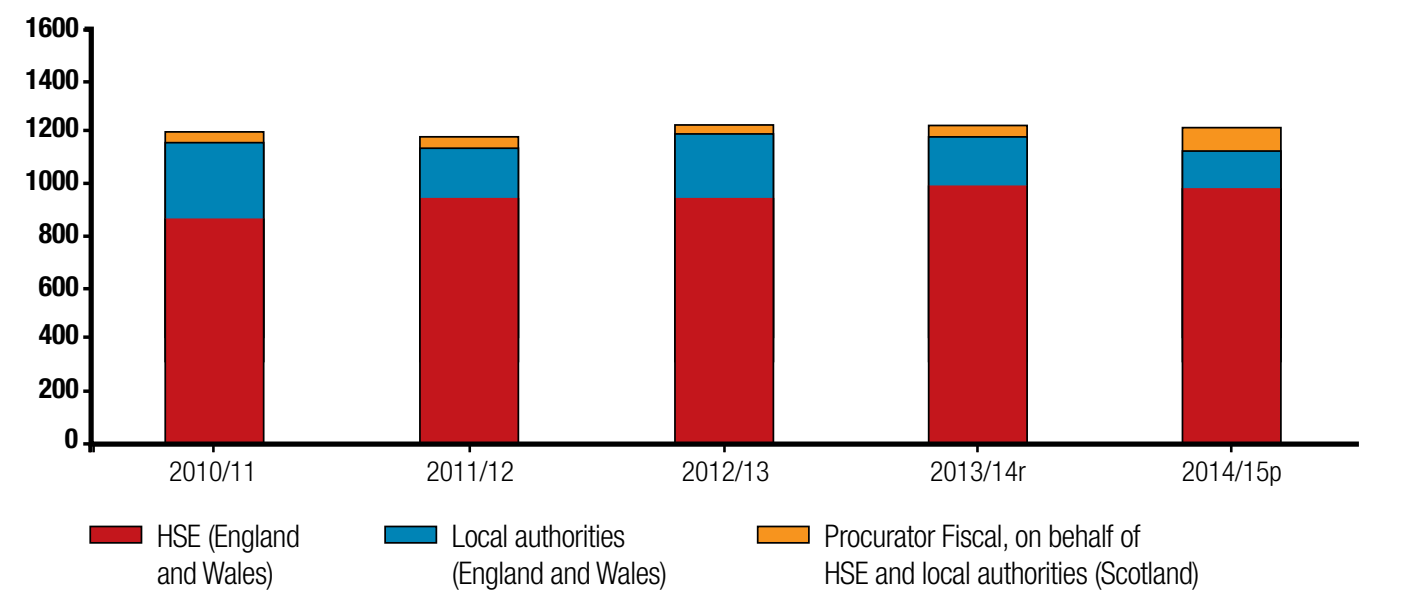

For further information, please go to www.hse.gov.uk/statistics/tables/ef3.xlsx

\begin{tabular}{c|c|c|c} 
& $\begin{array}{c}\text { HSE (England \& } \\
\text { Wales) }\end{array}$ & $\begin{array}{c}\text { Local authorities } \\
\text { (England \& Wales) }\end{array}$ & $\begin{array}{c}\text { Procurator Fiscal, on behalf } \\
\text { of HSE and local authorities } \\
\text { (Scotland) }\end{array}$ \\
\hline $\mathbf{2 0 1 0 / 1 1}$ & 878 & 283 & 45 \\
$\mathbf{2 0 1 1 / 1 2}$ & 951 & 198 & 41 \\
$\mathbf{2 0 1 2 / 1 3}$ & 957 & 240 & 32 \\
$\mathbf{2 0 1 3 / 1 4 r}$ & 984 & 191 & 44 \\
$\mathbf{2 0 1 4 / 1 5 p}$ & 979 & 142 & 90
\end{tabular}

$\boldsymbol{r}=$ revised $\quad \boldsymbol{p}=$ provisional 


\section{Enforcement notices}

There was a fall in the number of notices issued in 2014/15p compared to $2013 / 14 r$.

- 12,430 notices were issued by HSE and local authorities in $2014 / 15 p$, a decrease of $10 \%$ from the previous year.

- 9,446 enforcement notices were issued by HSE, a decrease of $7 \%$ from the previous year. In recent years the figure has fluctuated with no real trend.

- Local authorities issued 2,984 notices, down 19\% from the previous year, which continues the downward trend seen over the last five years.

Change indicator for

enforcement notices issued

\begin{tabular}{l} 
Since 2013/14 \\
\hline Since 2009/10 \\
Since 2004/05
\end{tabular}

$\boldsymbol{r}=$ revised $\quad \boldsymbol{p}=$ provisional

\section{Enforcement notices issued by HSE and local authorities} 2003/04 - 2014/15p

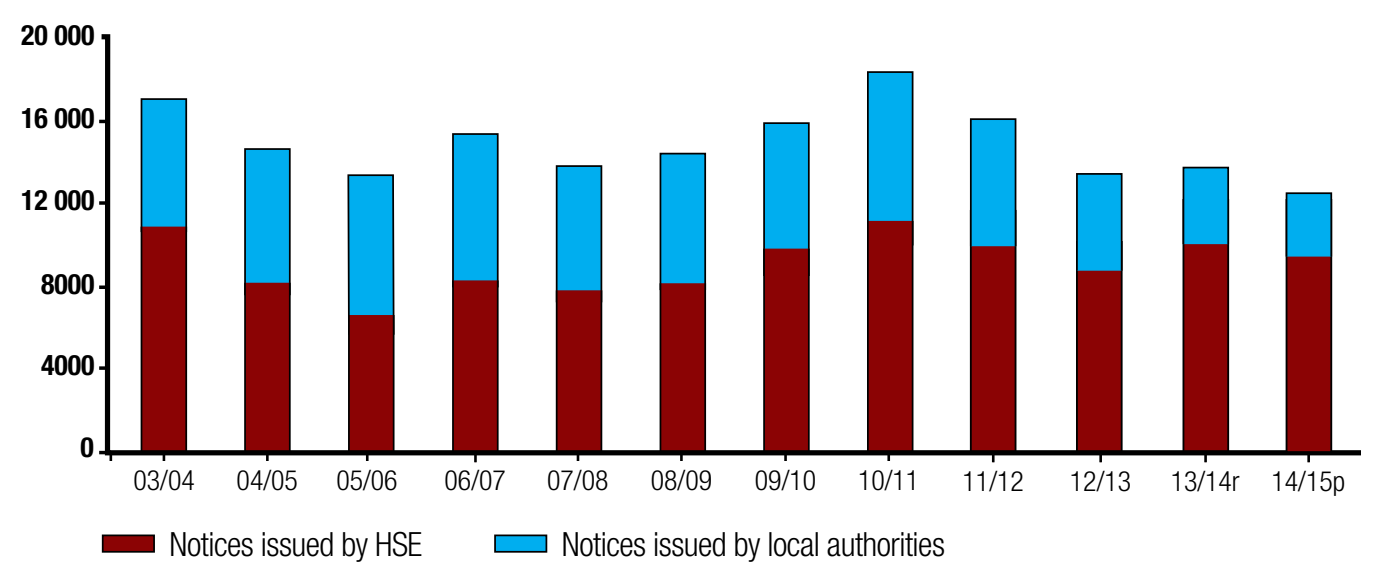

For further information, please go to www.hse.gov.uk/statistics/tables/ef6.xlsx

\begin{tabular}{r|r|r|r|r|c}
\multicolumn{2}{l|}{} & Improvement notice & Deferred prohibition & Immediate prohibition & Total \\
\hline \multirow{2}{*}{$\mathbf{2 0 1 2 / 1 3}$} & HSE & 5,752 & 17 & 3,038 & 8,807 \\
& Local authorities & 3,358 & 14 & 1,321 & 4,693 \\
& Total & $\mathbf{9 , 1 1 0}$ & $\mathbf{3 1}$ & $\mathbf{4 , 3 5 9}$ & $\mathbf{1 3 , 5 0 0}$ \\
\hline \multirow{2}{*}{$\mathbf{2 0 1 3 / 1 4 r}$} & HSE & 6,660 & 25 & 3,434 & 10,119 \\
& Local authorities & 2,412 & 24 & 1,235 & 3,671 \\
& Total & $\mathbf{9 , 0 7 2}$ & $\mathbf{4 9}$ & $\mathbf{4 , 6 6 9}$ & $\mathbf{1 3 , 7 9 0}$ \\
\hline $\mathbf{2 0 1 4 / 1 5 p}$ & HSE & 6,330 & 6 & 3,110 & 9,446 \\
& Local authorities & $\mathbf{1 , 9 5 8}$ & 19 & 1,007 & 2,984 \\
& Total & $\mathbf{8 , 2 8 8}$ & $\mathbf{2 5}$ & $\mathbf{4 , 1 1 7}$ & $\mathbf{1 2 , 4 3 0}$
\end{tabular}




\section{Sources and definitions}

\section{The Labour Force Survey (LFS)}

The LFS is a national survey run by the Office for National Statistics of currently around 41,000 households each quarter. HSE commissions annual questions in the LFS to gain a view of work-related illness and workplace injury based on individuals' perceptions. The analysis and interpretation of these data are the sole responsibility of HSE. See www.hse.gov.uk/statistics/lfs/technicalnote.htm for more details.

Self-reported work-related illness: People who have conditions which they think have been caused or made worse by their current or past work, as estimated from the LFS. Estimated total cases include longstanding as well as new cases. New cases consist of those who first became aware of their illness in the last 12 months. HSE has collected data on ill health through the LFS, periodically since 1990 and annually from $2003 / 04$ to $2011 / 12$. In $2012 / 13$, the ill health data collection was suspended but from 2013/14 returned to annual data collection.

Self-reported injuries: Workplace injuries sustained as a result of a non-road traffic accident, as estimated by the LFS. Over-3-day and over-7-day absence injuries include all those with more than three and more than seven consecutive (working and non-working) days away from work (not counting the day on which the accident happened).
HSE has collected data on injuries through the LFS in 1990 and annually since $1993 / 94$. LFS injury rates are generally presented as three-year averages to provide a more robust series of estimates.

Working days lost: Days off work due to workplace injuries and workrelated ill health, as estimated by the LFS. The figures are expressed as full-day equivalents, to allow for variation in daily hours worked, and are available for 2000/01 (injuries), 2001/02 (ill health), and annually (for both injuries and ill health) from 2003/04 to 2011/12. In 2012/13, the ill health data collection was suspended but from 2013/14 returned to annual data collection.

\section{RIDDOR}

The Reporting of Injuries, Diseases and Dangerous Occurrences Regulations (as amended), under which fatal and defined non-fatal injuries to workers and members of the public are reported by employers.

Certain types of work-related injury are not reportable under RIDDOR, hence excluded from these figures. Particular exclusions include fatalities and injuries to the armed forces and injuries from work-related road traffic collisions.

A number of key changes to the reporting system and legal requirements have occurred in recent years, with some impact on the resulting statistics: 
- September 2011: the notification system used by employers changed to a predominantly online system.

- April 2012: a legislative change introduced the requirement to report injuries to workers that lead to absence from work or inability to do their usual job, for over seven days (over-7-day injuries). This replaced the previous 'over-3-day' legal requirement.

- October 2013: more extensive legislative changes were introduced to simplify the reporting of workplace injuries. One key change was the introduction of 'specified injuries', which replaced the previous 'major injury' category. This change occurred half-way through the 2013/14 reporting year.

For more information about the coverage of RIDDOR and the effect on statistics of recent changes, see www.hse.gov.uk/statistics/sources.htm.

\section{Reports of ill health by specialist physicians and General Practitioners (THOR and THOR-GP)}

Reports of work-related ill health are gathered in surveillance schemes run by The Health and Occupation Reporting network (THOR); statistical tables covering patients seen by specialists are available annually from the early 1990s for work-related respiratory disorders and skin disease. In THOR-GP (since 2005), a sample of general practitioners are asked to report new cases of work-related ill health.
III health assessed for disablement benefit (IIDB)

New cases of specified 'prescribed diseases' (with an established occupational cause) assessed for compensation under the Industrial Injuries Disablement Benefit scheme. IIDB statistics are available annually from 2003 , although earlier historical data is available.

\section{Death Certificates}

Pages 2 and 3 refer to deaths from some types of work-related lung disease, including the asbestos-related diseases mesothelioma and asbestosis.

\section{Enforcement notices and offences prosecuted}

The enforcing authorities are HSE, Local Authorities and, in Scotland, the Crown Office and Procurator Fiscal Service (COPFS). In Scotland, HSE and local authorities investigate potential offences but cannot institute legal proceedings and the COPFS makes the final decision whether to institute legal proceedings and which offences are taken.

Enforcement notices cover improvement, prohibition and deferred prohibition. Offences prosecuted refer to individual breaches of health and safety legislation; a prosecution case may include more than one offence. Where prosecution statistics are allocated against a particular year, unless otherwise stated, the year relates to the date of final hearing with a known outcome. They exclude those cases not completed, for example adjourned. 


\section{HSE Costs to Britain Model}

Developed to estimate the economic costs of injury and new cases of ill health arising largely from current working conditions. The economic cost estimate includes estimates of both financial (or direct) costs incurred, either in terms of payments that have to be made or income/output that is lost and the monetary valuation of the impact on quality and loss of life of affected workers.

\section{European Survey of Enterprises on New and Emerging Risks (ESENER)}

A large Europe-wide survey carried out in 2014 of establishments with five or more employees including all sectors of economic activity except for private households (SIC 2007 Section T) and extraterritorial organisations (SIC 2007 Section U). The survey asked those 'who know best' about safety and health in establishments about the way safety and health risks are managed at their workplace, with a particular focus on psychosocial risks.

\section{Eurostat}

Fatal Injuries: Eurostat publishes data on fatal accidents at work standardised to take account of the different structure of working populations across European Union (EU) member states. For further details on the scope and coverage of the fatalities data please see: http://ec.europa.eu/eurostat/cache/metadata/en/hsw_acc_work_esms.htm
European Union Labour Force Survey (EU LFS): A large household survey carried out in the 28 Member States of the European Union, 2 candidate countries and 3 countries of the European Free Trade Association (EFTA). In 2013 the EU-LFS included an ad hoc module asking about accidents at work, work-related health problems, and exposure to factors that can adversely affect mental well-being or physical health in the previous 12 months.

\section{Definitions}

Rate per 100,000: The number of annual injuries or cases of ill health per 100,000 employees or workers, either overall or for a particular industry, occupation or area.

95\% confidence interval: The range of values which we are $95 \%$ confident contains the true value, in the absence of bias. This reflects the potential error that results from surveying a sample rather than the entire population.

Statistical significance: A difference between two sample estimates is described as 'statistically significant' if there is a less than $5 \%$ chance that it is due to sampling error alone.

Standard Industrial Classification (SIC): The system used in UK official statistics for classifying businesses by the type of activity they are engaged in. This has been revised several times since first introduced in 1948. The version used in this release is SIC 2007. 
Standard Occupational Classification (SOC): The system used in UK official statistics for classifying workers by the type of job they are engaged in. The version used in this release is SOC 2010.

Change indicators: The 'traffic light' indicators of change over the past year, five years and ten years which are shown on many pages of this document have been determined by statistical significance for LFS data and the cost model (i.e. whether the latest estimate is significantly higher or lower than the relevant reference year); and using a $2 \%$ per year threshold for RIDDOR and enforcement data (for example, if a data series has fallen by more than $2 \%$ per year over the reference period, a downward indicator is shown).
p: Provisional.
r: Revised (see HSE statistics revision policy on this page)

n/a: Not available.

\section{HSE statistics revision policy}

The Code of Practice for Official Statistics requires all producers of Official Statistics to publish a policy on revisions.

HSE aims to avoid the need for large revisions to National Statistics unless absolutely necessary and has procedures in place to minimise the number and scale of any revisions made. Where any changes to previously-published data come to the attention of HSE statisticians, they will form a professional view as to whether a revision to published data is in the public interest. If necessary, the HSE Chief Statistician will seek further advice from the National Statistician's office.

Data revisions have been marked within this document with an ' $r$ '. This includes figures published in 2013/14 as 'provisional' but which have since been finalised, and also in some cases to previously finalised data. A full revisions policy and log can be seen at www.hse.gov.uk/statistics/about/revisions/index.htm.

This outlines the main reasons why data revisions tend to occur, as well as detailing all large data revisions since July 2010. 


\section{Health and Safety Statistics 2014/15}

\section{National Statistics}

The RIDDOR, LFS, deaths from occupational lung diseases, THOR, IIDB, enforcement and Costs to Britain figures in this report are National Statistics.

National Statistics are produced to high professional standards set out in the National Statistics Code of Practice. They undergo regular quality assurance reviews to ensure that they meet customer needs. They are produced free from any political interference.

More information about our data sources can be found at www.hse.gov.uk/statistics/sources. htm.

For information regarding the quality guidelines used for statistics within HSE see www.hse.gov.uk/statistics/about/quality-guidelines.htm.

Additional data tables can be found at www.hse.gov.uk/statistics/tables/.

The statistics within this document refer to Great Britain only - for information on health and safety statistics in Northern Ireland please go to www.hseni.gov.uk/about-hseni/statistics.htm.

\section{HSE Chief Statistician: Alan Spence}

Contact: alan.spence@hse.gsi.gov.uk

Last updated: October 2015

Next update: October 2016 